\title{
ChemComm
}

\section{Synthetic modification of salinomycin: selective $O$-acylation and biological evaluation $\dagger$}

\author{
Cite this: Chem. Commun. 2013, \\ 49, 9944 \\ Received 5th August 2013, \\ Accepted 21st August 2013
}

DOI: $10.1039 / c 3 c c 45983 g$

\author{
Björn Borgström, ${ }^{a}$ Xiaoli Huang, ${ }^{b}$ Martin Pošta, ${ }^{a}$ Cecilia Hegardt, ${ }^{c}$ Stina Oredsson ${ }^{b}$ \\ and Daniel Strand*a
}

www.rsc.org/chemcomm

\begin{abstract}
Salinomycin has found renewed interest as an agent for prevention of cancer recurrence through selectively targeting cancer stem cells. Strategies for generation of improved salinomycin analogs by individual modification of its hydroxyl groups are presented. An evaluation of the dose-response effects of the resulting library on breast cancer cell lines shows that acylation of the C20 hydroxyl can be used to improve $\mathrm{IC}_{50}$ values down to one fifth that of salinomycin.
\end{abstract}

Cancer stem cells (CSCs) are a subpopulation of cancer cells that have been invoked in recurrence, multi-drug resistance, and metastasis of cancer. ${ }^{1}$ Some of these effects are likely related to a reduced sensitivity to conventional chemotherapy in these cells. ${ }^{1 a}$ Small molecules that selectively target the CSC population, either by inducing a phenotypical change or by inhibiting growth, thus constitute an important new avenue for preventing recurrence and metastasis of cancer as most current therapies do not address stem-like cancer cells. Methods to identify such compounds by high-throughput screening have been developed. ${ }^{2}$ Salinomycin $(\mathrm{SA}, \mathbf{1})^{3,4}$ was recently identified as the most selective in a library of more than 16000 compounds in reducing the proportion of putative CSCs in breast cancer cell lines as well as inhibiting mammary tumor growth in vivo. ${ }^{2}$ The mechanism by which SA influences the CSC population is not fully understood. ${ }^{5 a, b}$ Proposed modes of action include inhibition of P-glycoprotein gp170, ${ }^{5 c}$ interference of the Wnt signaling cascade, ${ }^{5 d}$ increased DNA damage and reduction of the protein p21 level, ${ }^{5 e}$ overcoming $\mathrm{ABC}$ transporter-mediated multidrug and apoptosis resistance, ${ }^{5 a}$ increasing oxidative stress, ${ }^{5 f}$ and increasing levels of reactive oxygen species. ${ }^{5 g, h}$ The recent surge of activity related to SA in the biomedical field has yet to transgress to the synthetic community; a report of $\mathrm{C} 1$ amides of SA being the exception. ${ }^{6}$

\footnotetext{
${ }^{a}$ Centre for Analysis and Synthesis, Department of Chemistry, Lund University, Box 124, 22100 Lund, Sweden. E-mail: daniel.strand@chem.lu.se; Fax: +46 (0)4622282 09; Tel: +46 (0)462228123

${ }^{b}$ Department of Biology, Lund University, Sweden

${ }^{c}$ Department of Oncology, Clinical Sciences, Lund University, Sweden

$\dagger$ Electronic supplementary information (ESI) available: Experimental procedures, NMR spectra of all new compounds and MTT dose-response curves. See DOI: $10.1039 / \mathrm{c} 3 \mathrm{cc} 45983 \mathrm{~g}$
}

Semi synthesis of analogs through selective chemical modification of SA constitutes an attractive avenue for identifying compounds with improved selectivity against CSCs and equally important, for advancing the structural understanding of the mode of action of SA against them. In particular, perturbation of the ion transport properties of SA by systematic manipulation of the substructures involved in ion binding is of value to this end as the antiporter properties of SA has been suggested as an origin for its CSC activity. ${ }^{7}$ Herein, we describe general and selective synthetic strategies for the individual modification of all hydroxyl groups in $\mathrm{SA}^{8}$ as well as an evaluation of the resulting analog library in breast cancer cells. Significantly, SA analogs acylated at the $\mathrm{C} 20$ hydroxyl displayed $\mathrm{IC}_{50}$ values down to one fifth that of the native structure against breast cancer cells in an MTT-based dose-response assay. The synthetic procedures described are of value for the development of improved SA derivatives as well as for the exploration of SAR for its CSC selectivity. ${ }^{9}$

Pioneering work detailed the use of aliphatic acid anhydrides to esterify the C20 hydroxyl group. ${ }^{3 b, 10}$ General access to such structures would be of particular value in a CSC context as such modifications resulted in an enhanced ion binding and activity in antibiotic assays. ${ }^{3}$ In our hands, this method was however limited to unhindered acid anhydrides and we were only able to isolate a subset of such structures in homogenous form in low yields. Towards circumventing these problems, reversible masking of the carboxylic acid of SA is a key enabling modification. Protection of this moiety enhances the stability of intermediates and facilitates both purification and characterization of intermediates in analog synthesis. Conversion of SA into the known methyl ester 3a was accomplished in good yield with TMSCHN $_{2}$ (Scheme 1). Attempts to hydrolyze this ester under basic conditions however proved to be unsuccessful. Also milder protocols including the use of $\mathrm{Me}_{3} \mathrm{SnOH}^{11}$ resulted in decomposition of the sensitive structure. A suitable protective group for the carboxylate, TMSEt-, could however be introduced in $61 \%$ yield, also on a multi-gram scale, using TCFH $^{12}$ as the coupling reagent. This result is noteworthy in light of the comparatively low nucleophilicity of TMSEtOH and the steric inaccessibility of the acid; the difficulty of using coupling reagents with SA has been commented on ${ }^{13}$ and a range 

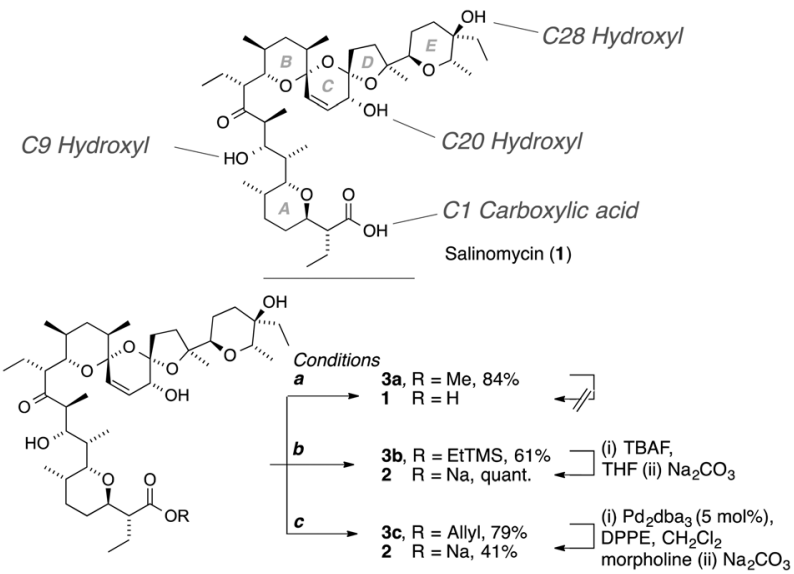

Scheme 1 Alkylation and deprotection of the carboxylic acid of SA. Conditions (a) $\mathrm{TMSCHN}_{2}$, toluene-MeOH 2: 1; (b) TMSEtOH, TCFH, DIPEA, $\mathrm{CH}_{2} \mathrm{Cl}_{2}, \mathrm{O}^{\circ}$; (c) $\mathrm{Cs}_{2} \mathrm{CO}_{3}$, allyl bromide, DMF.

of conventional coupling reagents (DCC, EDC/HOBt, HATU, PyBOP etc.) failed to give even trace amounts of ester $\mathbf{3 b}$. Importantly, SA could be quantitatively and tracelessly released from the TMSEt-ester $\mathbf{3 b}$ with TBAF in THF. Washing the crude product with $\mathrm{Na}_{2} \mathrm{CO}_{3}$ (aq.) gave the SA.Na salt (2), indistinguishable from the natural product, and pure by ${ }^{1} \mathrm{H}-$ and ${ }^{13} \mathrm{C}-\mathrm{NMR}$ spectroscopy. For an orthogonal alternative to TBAF deprotection, allyl ester $3 \mathbf{c}$ was also prepared by treatment of 2 with allyl bromide in the presence of $\mathrm{Cs}_{2} \mathrm{CO}_{3}$. Cleavage of this ester with $\operatorname{Pd}(0)$ returned SA in moderate yield (41\%).

In contrast to the SA or the SA-Na salt, protected $\mathbf{3 b}$ can be reacted cleanly and selectively with a variety of acid chlorides at the C20 hydroxyl (Scheme 2). Reactions of unprotected SA (or its $\mathrm{Na}$ salt) with $\mathrm{BzCl}, \mathrm{DMAP}$, and $\mathrm{Et}_{3} \mathrm{~N}$ or $\mathrm{Bz}_{2} \mathrm{O}$ gave either no reaction or extensive side product formation. We were unable to isolate benzoate $\mathbf{5 b}$ from any of these experiments. The TMSEt-esters of 4a-q could all be cleanly cleaved with TBAF and the products isolated as their sodium salts. In addition, C20 carbonates were readily formed from reactions with chloroformates. A C20-carbamoylated product was formed from the reaction

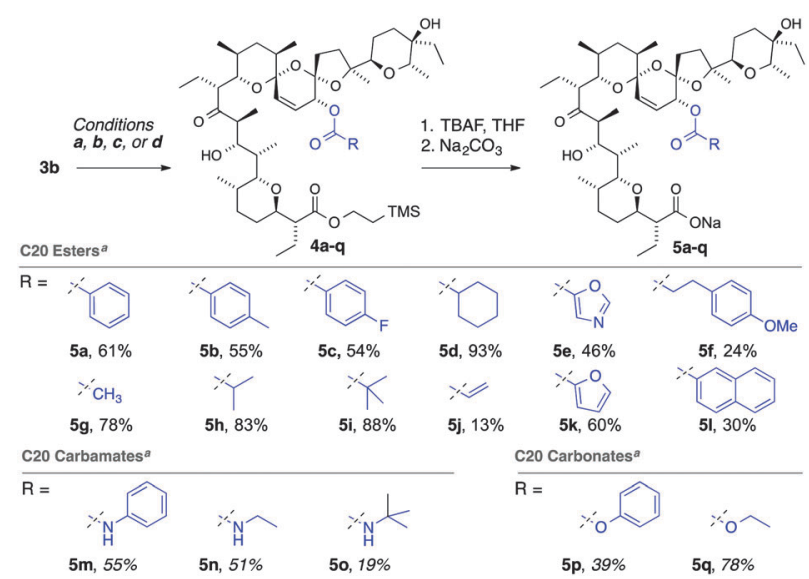

Scheme 2 Selective acylation at the 20-position. Conditions (a): RCOCl, DMAP, $\mathrm{Et}_{3} \mathrm{~N}, \mathrm{CH}_{2} \mathrm{Cl}_{2}\left(5 \mathrm{a}-5 \mathrm{ll}\right.$ ); (b) RNCO, $\mathrm{CH}_{2} \mathrm{Cl}_{2}(5 \mathrm{~m})$; (c) RNCO, CuCl, DMF (5n, 5o); (d) ROCOCl, DMAP, Et ${ }_{3} \mathrm{~N}, \mathrm{CH}_{2} \mathrm{Cl}_{2}(\mathbf{5} \boldsymbol{p}$ and $\mathbf{5 q}) .{ }^{a}$ Isolated yields over three steps.
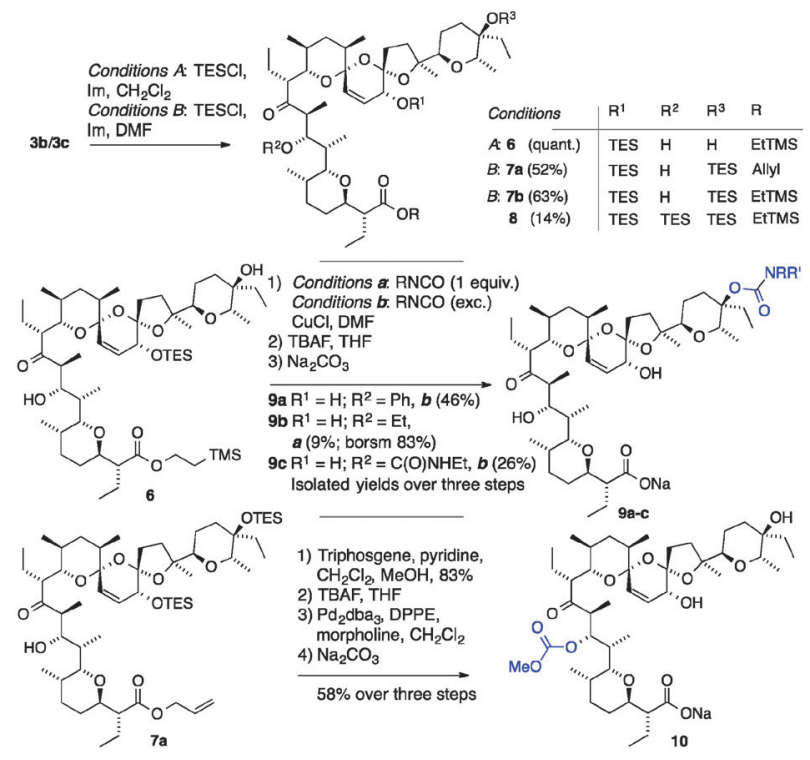

Scheme 3 Acylation of the C9 and C28 hydroxyls.

with PhNCO. Less reactive isocyanates (Et- and $t \mathrm{Bu}-)$ required addition of catalytic amounts of $\mathrm{CuCl}$ to react. ${ }^{14}$ After deprotection, carbamates and carbonates $\mathbf{5 m - 5 q}$ were isolated in good yields over three steps. To enable selective derivatization of the C9 and C28 alcohols, silyl groups were introduced (Scheme 3). Selective silylation of the $\mathrm{C} 20$ hydroxyl was accomplished quantitatively with TESCl and imidazole in $\mathrm{CH}_{2} \mathrm{Cl}_{2}$. Somewhat surprisingly, the most reactive alcohol of 6 was the tertiary alcohol at C28. Treatment of 6 with an excess of PhNCO and CuCl in DMF carbamoylated this position selectively. Excess EtNCO with $\mathrm{CuCl}$ gave allophenate $9 \mathrm{c}$ under the same conditions. By limiting the amount of isocyanate, ethyl carbamate $\mathbf{9 b}$ could also be isolated in low conversion. Removal of the protective groups with TBAF gave carbamates $\mathbf{9 a / b}$ and allophenate $9 \mathbf{c}$ in good yields over two steps. The position of the acyl groups at C28 was confirmed by diagnostic downfield shifts of the C28 signal in the respective ${ }^{13} \mathrm{C}-\mathrm{NMR}$ spectra (15.6-10.2 ppm) $\cdot{ }^{15}$ Towards modifying the least reactive C9 hydroxyl, bis-silylation of both the C20 and C28 alcohols of $\mathbf{3 b} \mathbf{b} \mathbf{c}$ was accomplished with TESCl in DMF. Minor amounts of tri-TES side-product were also isolated under these conditions. Global deprotection of tri-TES 8 with TBAF corroborated the retained stereochemical integrity of this compound; all four protective groups were cleanly removed and the SA.Na salt was obtained as a single diastereomer indistinguishable from the natural product by ${ }^{1} \mathrm{H}-\mathrm{NMR}$.

Acylation of the $\mathrm{C} 9$ alcohol was accomplished by reacting bis-TES $7 \mathbf{a} / \mathbf{b}$ with triphosgene followed by addition of methanol to give the corresponding methyl carbonates. Removal of the TMSEt-group with TBAF however proved to be incompatible with this modification due to competing elimination of the carbonate ${ }^{16}$ Instead, the use of allyl ester 7a provided a milder alternative; removal of the TES-groups by brief exposure to TBAF, followed by release of the carboxylic acid under $\operatorname{Pd}(0)$ catalysis gave carbonate 10 in $58 \%$ overall yield. The position of the carbonate at $\mathrm{C} 9$ was confirmed by a diagnostic HMBC correlation from the C9 proton to the carbonate carbonyl carbon. ${ }^{15}$ 
Table 1 Antiproliferative activity of acylated analogs of SA evaluated by an MTT-based dose-response assay ${ }^{a, b, c}$
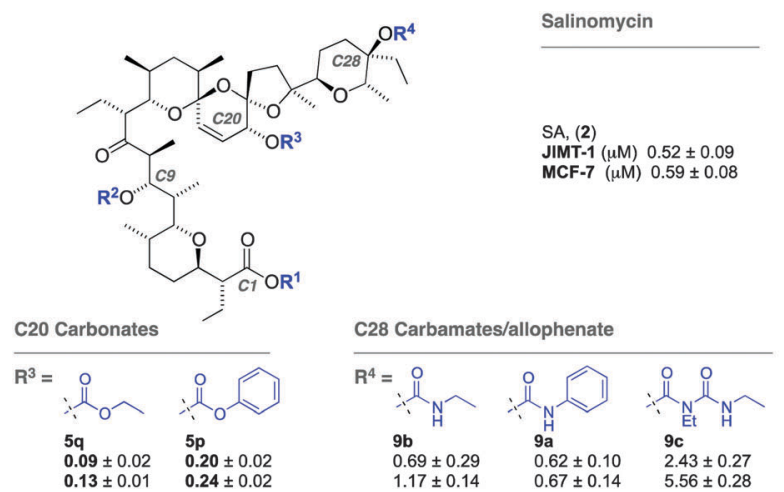
${ }^{a} \mathrm{IC}_{50}$ values are the mean $( \pm \mathrm{SE}$ ) for $50 \%$ reduction of MTT compared to control. MTT reduction is assumed to be directly proportional to the cell
number. For all entries (except for 3a) $n=3 .{ }^{b} \mathrm{R}^{1}=\mathrm{Na}$ and $\mathrm{R}^{2-4}=\mathrm{H}$, unless otherwise stated. ${ }^{c}$ Analog $5 \mathbf{l}$ is not soluble in DMSO and thus not tested.

The antiproliferative activity of the $O$-acylated analogs and methyl ester 3a was evaluated in MCF-7 and JIMT-1 breast cancer cells using an MTT assay (Table 1). The C20-acylated analogs displayed $\mathrm{IC}_{50}$ values lower or similar to that of SA in both cell lines. The enhancement of activity in antibiotic assays for C20 esters is thus carried over to cancer cells. The most potent C20 analogs in this assay proved to be those with the least bulky substituents in each series, ethyl carbonate $\mathbf{5 q}$, acetate $\mathbf{5 g}$, and ethyl carbamate $\mathbf{5 n}$. Analogs deprived of a stabilizing interaction between the carboxylate and the C9 hydroxyl (3a and 10) exhibited a significantly reduced activity. The retained activity of the C28 carbamates $\mathbf{9 a} / \mathbf{b}$ is in line with the previous suggestion that in membranes, unlike in the solid state, this group does not contribute to the ion-binding of SA by hydrogen bonding to the carboxylate. ${ }^{17}$

In summary, acylation of the C20 hydroxyl groups of the therapeutically promising compound SA gave analogs with $\mathrm{IC}_{50}$ values down to one fifth that of the native structure against cancer cells. Selective introduction of protective groups enables diverse access to analogs individually modified at the $\mathrm{C} 9, \mathrm{C} 20$, and $\mathrm{C} 28$ hydroxyl groups. Certain acyl derivatives of the $\mathrm{C} 28$ hydroxyl retain the activity of the parent compound whereas derivatization of positions directly involved in ion-binding reflects in a reduced activity. The strategies presented should be of significant value also for more elaborate modifications of SA. An extensive biological investigation of the CSC selectivity of these and related compounds and the correlation of this selectivity with antiporter activity is currently underway and will be reported in due course.

The Crafoord Foundation, the Magn Bergvall Foundation, The Royal Academy of Sciences, the Johan Hierta Foundation, the Mrs Berta Kamprad Foundation, the Percy Falk Foundation, and The Swedish Research Council are acknowledged for funding. We thank Prof. Lo Persson for insightful discussions.

\section{Notes and references}

1 For lead references, see: (a) M. Dean, T. Fojo and S. Bates, Nat. Rev. Cancer, 2005, 5, 275; (b) N. Y. Frank, T. Schatton and M. H. Frank, J. Clin. Invest., 2010, 120, 41; (c) K. Sampieri and R. Fodde, Semin. Cancer Biol., 2012, 22, 187; (d) For recent reviews, see: C. Naujokat and R. Steinhart, J. Biomed. Biotechnol., 2012, 2012, 950658.

2 P. B. Gupta, T. T. Onder, G. Jiang, K. Tao, C. Kuperwasser, R. A. Weinberg and E. S. Lander, Cell, 2009, 138, 645.
3 (a) Y. Miyazaki, M. Shibuya, H. Sugawara, O. Kawaguchi and C. Hirsoe, J. Antibiot., 1974, 27, 814; (b) Y. Miyazaki, H. Kinashi, N. Otake, M. Mitani and T. Yamanishi, Agric. Biol. Chem., 1976, 40, 1633.

4 For total synthesis of SA, see: (a) Y. Kishi, S. Hatakeyama and M. D. Lewis, in Frontiers of Chemistry, ed. K. J. Laidler, Oxford, 1982; (b) K. Horita, S. Nagato, Y. Oikawa and O. Yonemitsu, Chem. Pharm. Bull., 1989, 37, 1698; (c) P. J. Kocienski, R. C. D. Brown, A. Pommier, M. Procter and B. Schmidt, J. Chem. Soc., Perkin Trans. 1, 1998, 9.

5 (a) A. Huczyński, Chem. Biol. Drug Des., 2012, 79, 235; (b) A. Huczyński, Bioorg. Med. Chem. Lett., 2012, 22, 7002; (c) R. Riccioni, M. L. Dupuis, M. Bernabei, E. Petrucci, L. Pasquini, G. Mariani, M. Cianfriglia and U. Testa, Blood Cells, Mol., Dis., 2010, 45, 86; (d) D. S. Lu, M. Y. Choi, J. Yu, J. E. Castro, T. J. Kipps and D. A. Carson, Proc. Natl. Acad. Sci. U. S. A., 2011, 108, 13253; (e) J.-H. Kim, M. Chae, W. K. Kim, Y.-J. Kim, H. S. Kang, H. S. Kim and S. Yoon, Br. J. Pharmacol., 2011, 162, 773; $(f)$ K. Ketola, M. Hilvo, T. Hyötyläinen, A. Vuoristo, A.-L. Ruskeepää, M. Orešič, O. Kallioniemi and K. Iljin, Br. J. Cancer, 2012, 106, 99; $(g)$ B. Verdoodt, M. Vogt, I. Schmitz, S.-T. Liffers, A. Tannapfel and A. Mirmohammadsadegh, PLOS ONE, 2012, 7, e44132; (h) K.-Y. Kim, S.-N. Yu, S.-Y. Lee, S.-S. Chun, Y.-L. Choi, Y.-M. Park, C. S. Song, B. Chatterjee and S.-C. Ahn, Biochem. Biophys. Res. Commun., 2011, 413, 80.

6 (a) A. Huczyński, J. Janczak, M. Antoszczak, J. Wietrzyk, E. Maj and B. Brzezinski, Bioorg. Med. Chem. Lett., 2012, 22, 7146; (b) A. Huczyński, J. Janczak, J. Stefanska, M. Antoszczak and B. Brzezinski, Bioorg. Med. Chem. Lett., 2012, 22, 4697.

7 J. Tulla-Puche, Á. Torres, P. Calvo, M. Royo and F. Albericio, Bioconjugate Chem., 2010, 3, 555.

8 For examples of selective derivatization of hydroxyl groups in complex natural products, see: (a) J. González-Sabín, R. Morán-Ramallal and F. Rebolledo, Chem. Soc. Rev., 2011, 40, 5321; (b) R. Tong and J. J. Cheng, Chem. Sci., 2012, 3, 2234.

9 For the SAR of the antibiotic salinomycin, see ref. $3 b$.

10 P. Hammann, W. Raether and L. Vertesy, J. Antibiot., 1993, 46, 523.

11 K. C. Nicolaou, A. A. Estrada, M. Zak, S. H. Lee and B. S. Safina, Angew. Chem., Int. Ed., 2005, 44, 1378.

12 J. Tulla-Puche, Á. Torres, P. Calvo, M. Royo and F. Albericio, Bioconjugate Chem., 2008, 19, 1968.

13 A. Huczyński, J. Janczak, M. Antoszczak, J. Stefańska and B. Brzezinski, J. Mol. Struct., 2012, 1002, 197.

14 M. E. Duggan and J. S. Imagire, Synthesis, 1989, 131.

15 The full assignment was based on a combination of COSY, HMQC, and HMBC correlations. See ESI $\dagger$ for details.

16 HF.pyr in THF gave clean deprotection of the C20 O-TES group of 7a. Other fluoride sources (HF (aq), HF. $\mathrm{Et}_{3} \mathrm{~N}$, and $\mathrm{CsF}$ ) and solvents were screened but either led to elimination at $\mathrm{C} 9$, partial deprotection, or decomposition by cleavage across the C-ring, see; J. L. Wells, J. Bordner, P. Bowles and J. W. McFarland, J. Med. Chem., 1988, 31, 274.

17 (a) E. F. Paulus, M. Kurz, H. Matter and L. Vertesy, J. Am. Chem. Soc., 1998, 120, 8209; (b) N. Matsumori, A. Morooka and M. Murata, J. Am. Chem. Soc., 2007, 129, 14989. 